\title{
Delayed anaphylaxis, angioedema, or urticaria after consumption of red meat in patients with IgE antibodies specific for galactose- $\alpha-1,3-$ galactose
}

\author{
Scott P. Commins, MD, PhDa, Shama M. Satinover, MS ${ }^{a}$, Jacob Hosen, BS ${ }^{a}$, Jonathan \\ Mozena, MD $^{\mathrm{b}}$, Larry Borish, MD ${ }^{\mathrm{a}}$, Barrett D. Lewis, MD $^{\mathrm{c}}$, Judith A. Woodfolk, MBChB, PhD ${ }^{\mathrm{a}}$, \\ and Thomas A. E. Platts-Mills, MD, PhDa \\ ${ }^{a}$ Asthma and Allergic Diseases Center, University of Virginia Health System, Charlottesville \\ ${ }^{b}$ Allergy and Asthma Associates of Fredericksburg, Va \\ 'Ferrell-Duncan Clinic, Springfield, Mo
}

\section{Abstract}

\begin{abstract}
Background-Carbohydrate moieties are frequently encountered in food and can elicit IgE responses, the clinical significance of which has been unclear. Recent work, however, has shown that IgE antibodies to galactose- $\alpha-1,3$-galactose ( $\alpha$-gal), a carbohydrate commonly expressed on nonprimate mammalian proteins, are capable of eliciting serious, even fatal, reactions.
\end{abstract}

Objective-We sought to determine whether $\operatorname{IgE}$ antibodies to $\alpha$-gal are present in sera from patients who report anaphylaxis or urticaria after eating beef, pork, or lamb.

Methods-Detailed histories were taken from patients presenting to the University of Virginia Allergy Clinic. Skin prick tests (SPTs), intradermal skin tests, and serum IgE antibody analysis were performed for common indoor, outdoor, and food allergens.

Results-Twenty-four patients with IgE antibodies to $\alpha$-gal were identified. These patients described a similar history of anaphylaxis or urticaria 3 to 6 hours after the ingestion of meat and reported fewer or no episodes when following an avoidance diet. SPTs to mammalian meat produced wheals of usually less than $4 \mathrm{~mm}$, whereas intradermal or fresh-food SPTs provided larger and more consistent wheal responses. CAP-RAST testing revealed specific IgE antibodies to beef, pork, lamb, cow's milk, cat, and dog but not turkey, chicken, or fish. Absorption experiments indicated that this pattern of sensitivity was explained by an IgE antibody specific for $\alpha$-gal.

Conclusion-We report a novel and severe food allergy related to IgE antibodies to the carbohydrate epitope $\alpha$-gal. These patients experience delayed symptoms of anaphylaxis, angioedema, or urticaria associated with eating beef, pork, or lamb.

\section{Keywords}

Anaphylaxis; urticaria; food allergy; galactose- $\alpha-1 ; 3$-galactose; cross-reactive carbohydrate determinant

\footnotetext{
(C) 2009 American Academy of Allergy, Asthma \& Immunology

Reprint requests: Thomas A. E. Platts-Mills, MD, PhD, Allergy Division, PO Box 801355, University of Virginia Health System, Charlottesville, VA 22908-1355. tap2z@ virginia.edu.

Disclosure of potential conflict of interest:

The rest of the authors have declared that they have no conflict of interest.
} 
Establishing the cause of recurrent anaphylaxis is one of the primary goals of management because identification of responsible allergens remains a key step for avoiding further exposure or for recommending specific immunotherapy. In studies in which the cause of anaphylaxis has been established, foods or venom cause most reactions, ${ }^{1,2}$ and classically, these IgE-mediated reactions are thought to occur within 5 to 30 minutes after ingestion or injection of an offending agent but can occasionally occur up to 2 hours later. ${ }^{3}$ Numerous epitopes responsible for IgE-mediated food allergy have been described and are primarily protein based. ${ }^{4}$ Although it is well known that the carbohydrate moieties present on many plant foods can induce anti-glycan IgE responses, the clinical significance of these crossreactive carbohydrate determinants is unclear. ${ }^{5-10}$ By contrast, recent work has shown that $\operatorname{IgE}$ antibodies specific for the carbohydrate galactose- $\alpha$-1,3-galactose ( $\alpha$-gal) are capable of eliciting serious, even fatal, reactions. ${ }^{11}$

$\alpha$-Gal is produced by the enzyme $\alpha-1,3$-galactosyltransferase, and the naturally occurring $\operatorname{IgG}$ to $\alpha$-gal is responsible for mediating the hyperacute rejection of pig-to-primate xenotrans-plantation. ${ }^{12} \mathrm{IgG}$ antibodies against $\alpha$-gal are present in all nonimmunocompromised human subjects and constitute about $1 \%$ of circulating immunoglobulins in human subjects, apes, and Old World monkeys. ${ }^{13}$ While investigating the IgE antibodies in sera of patients who experienced a hypersensitivity reaction to the chimeric $\mathrm{mAb}$ cetuximab, Chung et a ${ }^{11}$ identified control patients without cancer who also had serum IgE antibodies that bound to cetuximab. These IgE antibodies were shown to be specific for an $\alpha$-gal moiety found on the asparagine at position 88 in the murine heavy chain portion of cetuximab. ${ }^{14}$

Because $\alpha$-gal is known to be present on tissues (notably thyroglobulin ${ }^{15}$ ) from nonprimate mammals, ${ }^{16}$ we investigated whether IgE antibodies to $\alpha$-gal were present in the sera of adult patients reporting reactions to beef. Further screening of sera from patients in the clinic led to the identification of patients with a positive titer of these antibodies whose primary symptoms were recurrent episodes of anaphylaxis, angioedema, or urticaria. Here we report the identification of 24 patients who have IgE antibodies to $\alpha$-gal and presented because of anaphylaxis, angioedema, or urticaria. These patients have no oral allergy syndrome-type symptoms; report delayed systemic symptoms associated with eating beef, pork, or lamb; and have a consistent pattern of both skin testing and serum IgE antibody results.

\section{METHODS}

\section{Patients and control subjects}

The studies reported here were approved by the University of Virginia Human Investigation Committee. Screening for IgE antibodies to $\alpha$-gal began with 4 patients who reported an allergy to beef and presented at the University of Virginia Allergy Clinic. Each of these 4 subjects had positive results on testing for IgE antibodies to $\alpha$-gal. We subsequently screened 243 patients presenting to the University of Virginia Allergy Clinic (Table I). This resulted in the identification of 15 further patients with $\operatorname{IgE}$ antibodies to $\alpha$-gal who had a titer of greater than $1.0 \mathrm{IU} / \mathrm{mL}$, all of whom reported reactions occurring after eating red meat (Table II). Sera from a further 21 of the 243 patients were found to have a titer of $\operatorname{IgE}$ antibodies to $\alpha$-gal of less than $1.0 \mathrm{IU} / \mathrm{mL}$. The screening also included sera from a cohort of 28 random patients with chronic idiopathic urticaria and 25 control patients, as well as patients with asthma, anaphylaxis, chronic sinusitis, and atopic dermatitis (see Table E1 in this article's Online Repository at www.jacionline.org). An additional 5 patients presenting to the Ferrell-Duncan Clinic in Springfield, Missouri, with similar histories of delayed reactions to mammalian meat were also found to be positive for IgE antibodies to $\alpha$-gal. These 24 patients ( 4 initial patients plus 15 University of Virginia Clinic patients plus 5 Missouri patients) were enrolled as subjects between November 2007 and May 2008. Sera 
from patients with atopic dermatitis, whose serum $\operatorname{IgE}$ antibody titers to other allergens were known, were also screened for IgE antibodies to $\alpha$-gal. ${ }^{17}$

\section{Skin testing}

Skin prick tests (SPTs) were performed on the volar surface of the arm by using a lancette (Prick Lancetter; Hollister-Stier, Spokane, Wash) after histamine $(1.8 \mathrm{mg} / \mathrm{mL})$ reactivity was verified. Commercially available skin testing reagents at 1:20 wt/vol were purchased from Greer (Lenoir, NC). Fresh-food SPTs were also performed in 5 patients. Fresh beef, pork, lamb, and chicken meats were procured from a local organic butcher on each day of testing. The fresh-food extracts were prepared as an approximate $10 \% \mathrm{wt} / \mathrm{vol}$ slurry in $50 \%$ glycerin/ saline by means of mortar and pestle homogenization of each meat. Total protein concentration was assayed by using the Bradford protein assay according to manufacturer's specifications to ensure equivalence to SPT reagents. In addition, the concentration of $\alpha$-gal was quantitated in the fresh extracts and SPT reagents by means of inhibition RIA (see Table E2 in this article's Online Repository at www.jacionline.org). In instances in which SPTs produced a wheal of less than $4 \mathrm{~mm}$ in diameter, intradermal testing was performed with $0.03 \mathrm{~mL}$ of a 1:100 dilution of commercially available reagents (ie, 1:2000 wt/vol) by using a 25-gauge needle. SPTs and intradermal tests were measured 15 minutes after placement. Negative controls were 50\% glycerin/saline for SPTs and buffered saline for intradermal tests.

\section{ImmunoCAP IgE assays}

Total and specific IgE antibodies were measured by using either commercially available ImmunoCAP (Phadia US, Portage, Mich) or a modification of the assay with streptavidin on the solid phase. ${ }^{18,19}$ The assays were performed with the ImmunoCAP 250 instrument, and the results were expressed as international units per milliliter, where the international unit both for specific and total IgE is approximately $2.4 \mathrm{ng}$. For specific assays, the standard cutoff point for a positive reaction was $0.35 \mathrm{IU} / \mathrm{mL}$. The streptavidin CAP technique was also used to measure IgE antibodies to $\alpha$-gal and purified (using mAb $6 \mathrm{~F}^{20}$ ) cat allergen Fel $\mathrm{d} 1$, where approximately $2 \mu \mathrm{g}$ of biotinylated antigen was added to each CAP before adding $40 \mu \mathrm{L}$ of undiluted serum. Sera were tested with commercially available assays for IgE antibodies to dust mite (Dermatophagoides pteronyssinus), cat, dog, grass pollen, beef, pork, lamb, chicken, turkey, codfish, cow's milk, and bromelain to investigate cross-reactivity.

\section{Absorption experiments}

Absorption assays were carried out with $\alpha$-gal or beef thyroglobulin bound to sepharose beads. Gal 1 1-3Gal $\beta-\mathrm{OCH}_{2} \mathrm{CH}_{2} \mathrm{CH}_{2} \mathrm{NH}$-sepharose was purchased from Glycotech (Gaithersburg, Md). Beef thyroglobulin (Sigma-Aldrich, St Louis, Mo) was conjugated to cyanogen bromide-activated sepharose 4B beads (GE Healthcare, Piscataway, NJ), as directed. Briefly, $70 \mathrm{mg}$ of protein was incubated with $2 \mathrm{~g}$ of $\mathrm{HCl}$-activated sepharose beads overnight at $4^{\circ} \mathrm{C}$, and unbound sites were blocked with $1 \%$ BSA the next day. Beads were stored as a slurry at a $1: 10$ bead/PBS ratio at $4^{\circ} \mathrm{C}$. Mock-coupled beads were created concurrently for control absorption studies. Absorption experiments were performed by incubating $500 \mu \mathrm{L}$ of serum and $50 \mu \mathrm{L}$ of bead slurry rotating overnight at $4^{\circ} \mathrm{C}$. Sera was spun to remove beads and assayed for remaining specific and total IgE levels. IgE-specific ImmunoCAP results were adjusted for changes in serum concentrations during the absorption process by measuring transferrin levels by means of ELISA (Bethyl Laboratories, Inc, Montgomery, Tex). 


\section{Statistical analysis}

We compared quantitative measures of IgE antibodies by using the Spearman rank-order correlation, and the Student $t$ test was used to compare results generated with the absorption assay. A 2 -sided $P$ value of less than .05 was considered to indicate statistical significance. Statistical analyses were performed with SPSS software, version 16.0 (SPSS, Inc, Chicago, Ill).

\section{RESULTS}

We have identified 24 patients with similar histories of delayed anaphylaxis, angioedema, or urticaria, each of whom has detectable IgE antibodies to $\alpha$-gal (Table II). All of the 24 patients self-reported race as "white," and most of the patients described the onset of anaphylaxis, angioedema, or urticaria as occurring without an obvious immediate trigger or provoking event. On detailed questioning, however, patients consistently reported that episodes were associated with having eaten beef, pork, or lamb 3 to 6 hours earlier. The range in time delay from 3 to 6 hours represents the entire cohort of patients, as most patients described symptoms occurring in a consistent time frame. There were 2 exceptions, however. One patient reported 2 episodes of anaphylaxis that occurred while exercising within 2 hours after eating beef. Another patient described the onset of itching and hives 45 minutes after eating beef and pork ribs, with symptoms progressing to anaphylaxis over 2 hours. Several patients described nausea, diarrhea, or indigestion before a reaction; however, the most commonly reported heralding symptom was itching (15/24 patients). Interestingly, among the patients noting a symptom before anaphylaxis, angioedema, or urticaria, the appearance of this symptom was not consistent. Given the delayed nature of the episodes, many reactions occurred late at night or awakened the patients from sleep. In fact, of the patients who experienced anaphylaxis, 5 of 10 had records of repeated treatments in emergency departments between 11 рм and 2 ам. Moreover, the time delay made diagnosis challenging because some patients had not associated eating mammalian meat with the occurrence of their symptoms. By contrast, several patients were enrolled while practicing an appropriate, self-initiated avoidance diet. In either situation patients reported fewer or no episodes when avoiding beef, pork, and lamb (Table II).

Skin testing with the prick technique showed responses from 2 to $5 \mathrm{~mm}$ (Table II and Fig 1). Given the relatively high titer of specific IgE to beef (Table II and Fig 2, A), reactivity to commercial extracts used in SPTs was surprisingly small (often a wheal of $<4 \mathrm{~mm}$ ). Using the commercial reagents in a double-prick manner did not produce large skin responses. The results of conventional prick-prick food testing with fresh meats did not differ from those of SPTs with commercially available reagents (data not shown). Preparation of beef, pork, and lamb extracts from fresh meat, however, did result in larger and more reliable SPT responses (Table III and Fig 1,C). RIA quantitation of $\alpha$-gal showed that, as judged by the dilution producing 30\% inhibition, there were significantly higher amounts of $\alpha$-gal in beef and pork from fresh food extracts compared with commercial reagents (the difference in lamb did not meet statistical significance). In cases in which SPTs produced a wheal of less than $4 \mathrm{~mm}$, intradermal testing was performed and produced positive reactions (wheal $\geq 8 \mathrm{~mm}$; Tables II and III and Fig $1, B$ ) that were reproducible. Consistent with nonreactive SPTs and intradermal tests for chicken, turkey, and codfish, as well as fresh chicken meat extract, inhibition RIA quantitation of $\alpha$-gal was negative for each of these fresh and commercial reagents (Fig 1 and see Table E2 online).

In keeping with the known distribution of $\alpha$-gal, the results of serum assays for $\operatorname{IgE}$ antibodies to beef, pork, lamb, cow's milk, cat, and dog were positive in the majority of the 24 sera (Fig 2, $A$ ). The lack of reactivity seen on skin testing to chicken, turkey, and fish was supported by sera being consistently negative for IgE antibodies to these allergens (Fig 2, 
A). Although 11 of the patients had IgE antibodies to grass pollen and 6 had $\operatorname{IgE}$ antibodies to dust mite, 6 of the 24 patients reported seasonal or perennial allergic symptoms (Fig 2, A, and data not shown). Screening sera from 243 patients presenting to the University of Virginia Allergy Clinic for IgE antibodies to $\alpha$-gal identified 15 cases and 241 additional sera with low-titer $(<1.0 \mathrm{IU} / \mathrm{mL})$ positive results (Table I and Table E1 in this article's Online Repository at www.jacionline.org). Of the 207 sera negative for IgE antibodies to $\alpha$ gal, 23 random sera were screened for the full panel of antigens, as reported in Fig 2, A. There were 9 sera positive to cat ( 6 also positive to Fel d 1), 7 to timothy grass, 6 to dog, and 5 to dust mite. None of the 23 sera were positive to beef, pork, lamb, chicken, codfish, or turkey. The 5 patients from Missouri were identified based on the clinical history of delayed reactions to mammalian meats, and the sera screened positive to $\operatorname{IgE}$ antibodies to $\alpha$-gal. Consistent with the other positive sera, the 5 from Missouri also were positive to beef, pork, lamb, cow's milk, cat, and dog (Fig 2, A). Analysis of serum IgE antibody results shows a significant correlation between IgE antibodies to $\alpha$-gal (geometric mean, $26.7 \mathrm{IU} / \mathrm{mL}$ ) and IgE antibodies to beef $(8.9 \mathrm{IU} / \mathrm{mL} ; r=0.87, P<.001$; Fig $2, B)$. Surprisingly, the titers of IgE antibodies to cat $(9.7 \mathrm{IU} / \mathrm{mL})$ and $\operatorname{dog}(10.4 \mathrm{IU} / \mathrm{mL})$ epithelia were very similar, and the correlation between the 2 was highly significant $(r=0.98, P<.001$; Fig $2, C)$. In these patients IgE antibodies to cat were not explained by sensitivity to Fel d $1(r=0.35, P=.17$; Fig 2,D).

The results from absorption experiments show that $\alpha$-gal bound to sepharose beads was capable of significantly reducing specific IgE antibody binding to $\alpha$-gal, beef, pork, cat, and $\operatorname{dog}(P<.01 ;$ Fig $3, A)$. Similarly, use of sepharose-bound bovine thyroglobulin also depleted specific IgE antibody binding $(P<.01 ; \mathrm{Fig} 3, A)$. In fact, bovine thyroglobulin absorbed binding to a greater extent than did $\alpha$-gal, likely because of the heavy saturation of $\alpha$-gal moieties on beef thyroglobulin. ${ }^{15}$ In parallel experiments with sera from patients with atopic dermatitis, preincubation of sera with sepharose-bound $\alpha$-gal or bovine thyroglobulin had no effect on the presence of allergen-specific IgE antibodies (Fig 3, B and $C$ ). As expected, absorption of sera with sepharose-bound $\alpha$-gal or sepharose-bound bovine thyroglobulin did not affect the levels of IgE antibodies to chicken, turkey, and codfish (Fig 3 and data not shown).

\section{DISCUSSION}

The current report contains several new observations. First, the patients report anaphylaxis, angioedema, or urticaria associated with eating mammalian meat 3 to 6 hours earlier. This represents a departure from the conventional food allergy paradigm and might provide an explanation as to why the clinical implications of $\operatorname{IgE}$ antibodies to carbohydrate epitopes have not been well characterized to date. ${ }^{21}$ Skin responses do occur with appropriate testing, indicating that $\operatorname{IgE}$ antibodies to $\alpha$-gal are present on mast cells, and therefore the delay in symptoms is likely due to digestion, processing, or both of the antigen.

Second, we have been able to relate distinct clinical symptoms to the newly described $\operatorname{IgE}$ antibody specific for $\alpha$-gal. The $\alpha$-gal epitope is abundantly expressed on cells and tissues of nonprimate mammals, ${ }^{15,22}$ making it potentially more clinically relevant than the previously described cross-reactive carbohydrate determinant motifs of xylose and core-3-linked fucose. ${ }^{23}$ Screening of sera from the 24 patients with IgE antibodies to $\alpha$-gal revealed that only 3 of the 24 had cross-reactivity to bromelain, which contains both xylose and core-3linked fucose (data not shown). Moreover, sera with high titer-specific IgE antibodies to bromelain did not contain IgE antibodies to $\alpha$-gal (data not shown). $\alpha$-Gal has not been previously described as a potential food allergen, and its elucidation might explain earlier published reports of delayed food (meat) allergy, ${ }^{24}$ eosinophilic gastroenteritis, ${ }^{25}$ or an observed reactivity to beef in children allergic to cow's milk. ${ }^{26}$ 
Third, in this cohort of patients with similar histories, symptoms, and serum IgE antibody profiles, we found that conventional SPTs with commercial reagents were insufficient for diagnosis. In fact, a wheal response of less than $4 \mathrm{~mm}$ to beef, pork, and lamb performed by using an accepted SPT method with widely used extracts could lead to incorrect guidance for patients, a serious issue when anaphylaxis is the result. Moreover, given the titer of $\operatorname{IgE}$ antibodies to $\alpha$-gal, both SPTs and intradermal tests produce smaller-diameter wheals than would be expected with a protein food allergen, such as peanut. There are several possible explanations for the intermediate skin test responses. It has been suggested that antibodies to relatively uncharged carbohydrate epitopes would have low affinity. ${ }^{27}$ Alternatively, the distribution of the $\alpha$-gal epitope on the intact proteins might not be suitable for cross-linking IgE antibodies on the surface of a mast cell. Despite the obvious logistic challenges, SPTs with freshly prepared food extracts offer an alternative approach with increased diagnostic benefits. We are currently pursuing data to demonstrate positive double-blind, placebocontrolled food challenge results in these patients to document symptoms and the time delay described. If we are able to do so, then the potential exists for using intradermal tests to foods because these patients would meet the proposed criteria. ${ }^{28}$ Finally, most patients reported the onset of symptoms within the last 2 to 3 years, challenging the notion that the incidence of adult-onset mammalian meat allergy is rare.

Screening serum samples from multiple geographic locales has revealed a distinct regional distribution of IgE antibodies to $\alpha$-gal. To date, we have found patients in Virginia, North Carolina, Tennessee, Arkansas, and Missouri, a distribution that roughly correlates with the higher incidence of cetuximab hypersensitivity reactions. ${ }^{11,29,30}$ This population is enriched, however, and other data suggest that the prevalence of IgE antibodies to $\alpha$-gal in central Virginia might be approximately $10 \%$. Thus our current data cannot be used to calculate the prevalence of $\operatorname{IgE}$ antibodies to $\alpha$-gal in patients with symptoms, nor does it provide evidence about what percentage of patients with IgE antibodies to $\alpha$-gal will have symptoms.

Initial attempts to clarify the possible causes of development of IgE antibodies to $\alpha$-gal included investigation of parasitic infections as an inciting event. Sera from patients with documented helminth infections, however, do not consistently contain IgE antibodies to $\alpha$ gal (data not shown). Interestingly, more than $80 \%$ of the patients in the present cohort report being bitten by ticks before having symptoms; a similar scenario has been recently described in a group of Australian patients. ${ }^{31}$ Therefore the implications of IgE antibodies to $\alpha$-gal might extend well beyond the southeastern United States, and we are pursuing the possibility that bites from ticks or tick larvae of the genus Amblyomma are responsible for triggering the production of IgE antibodies to $\alpha$-gal.

It has recently been reported that some patients with cat allergy have IgE antibodies that bind to a carbohydrate epitope on cat IgA, a major component of cat epithelium-derived allergy extracts. ${ }^{32}$ Further preliminary investigation suggests that these IgE antibodies are binding to an $\alpha$-gal moiety on cat $\operatorname{IgA}(\mathrm{M}$. van Hage, personal communication). Moreover, IgE antibodies to $\alpha$-gal might explain the clinical observation in Europe of an association between allergy to epithelia and allergy to meat (pork-cat syndrome), ${ }^{33}$ as well as the reported observation of cross-reactivity among beef, pork, and pet dander in patients with milk allergy. ${ }^{34}$ The significant correlation between IgE to cat and IgE antibodies to $\alpha$-gal is not because patients with IgE to $\alpha$-gal have cat allergy; in fact, only 3 of the 24 patients report allergic symptoms to cats, and these correspond to patients with $\operatorname{IgE}$ to Fel $\mathrm{d} 1$. Rather, the presence of $\alpha$-gal moieties on epithelia is responsible for the consistently positive cat (and dog) values, and this is supported by the absorption data showing that preincubation with $\alpha$-gal or beef thyroglobulin removed this IgE antibody (Fig 3). This apparent incongruence between ImmunoCAP results and clinical symptoms is also evident in the 
context of cow's milk because most patients tolerate milk despite positive skin test results and serum titers (geometric mean, $2.80 \mathrm{IU} / \mathrm{mL}$ ). Ten of the 24 patients reported symptoms to cow's milk, however, and the distinction between cow's milk reactions and the lack of cat/ dog allergic symptoms in the setting of seropositivity for each likely is because of the ingestion versus inhalant routes of exposure. Although avoidance of mammalian meat is certainly the recommendation, patients do not appear to require complete avoidance of all mammalian products (ie, the aforementioned tolerance of cow's milk in 14/24 patients). In fact, some patients even report the ability to tolerate small amounts of mammalian meat on occasion without symptoms but then might react to a single piece of bacon, raising the possibility that portion size, processing, preparation, and/or cut of meat might influence the production of a reaction. Another possibility is that a bovine allergen distinct from $\alpha$-gal is responsible for producing the reactions these patients have experienced.

In conclusion, we have described a cohort of patients with IgE antibodies to $\alpha$-gal who experience delayed symptoms of anaphylaxis, angioedema, or urticaria after eating mammalian meat. This report of severe food allergy related to IgE antibodies to a carbohydrate epitope is novel, and in keeping with the lack of immediate oral symptoms, skin testing in these patients often produces a wheal response of less than $4 \mathrm{~mm}$. There are 2 major questions that will require further research, the first of which might require controlled food challenges. Why are reactions to meat delayed for several hours? What insult or exposure induces the production of IgE antibodies to $\alpha$-gal in these adult patients?

Clinical implications: In patients with $\operatorname{IgE}$ antibodies to the carbohydrate $\alpha$-gal, eating beef, pork, or lamb is associated with delayed anaphylaxis, urticaria, or angioedema and often a less than 4-mm response on SPTs.

\title{
Supplementary Material
}

Refer to Web version on PubMed Central for supplementary material.

\section{Acknowledgments}

\begin{abstract}
We thank Staffan at Phadia for graciously providing laboratory equipment, reagents, and supplies. Additionally, we are indebted to the Organic Butcher of Charlottesville for being a reputable source of meats.

Supported by National Institutes of Health grant RO1 AI-20565, by AI-AADCRC-U19-070364, and by an American Academy of Allergy, Asthma \& Immunology/Glaxo-SmithKline fellow career development award and T32 AI007496-14 to S.P.C.

S. P. Commins received grant support from GlaxoSmithKline. J. Mozena is on the speakers' bureau for Meda. L. Borish is on the speakers' bureau for Merck and the advisory board for Genetech and received grant support from Genentech. J. A. Woodfolk received grant support from the National Institutes of Health/National Institute of Allergy and Infectious Diseases and is a member of the American Association of Immunologists and the Society for Investigative Dermatology. T. A. E. Platts-Mills is on the scientific advisory committee for Indoor Biotechnologies and receives grant support from Phadia, ImClone, and the National Institute of Allergy and Infectious Diseases.
\end{abstract}

\section{Abbreviations used}

a-gal Galactose- $\alpha-1,3$-galactose

SPT Skin prick test

\section{REFERENCES}

1. Kemp SF, Lockey RF, Wolf BL, Lieberman P. Anaphylaxis: a review of 266 cases. Arch Intern Med. 1995; 155:1749-1754. [PubMed: 7654108] 
2. Yocum MW, Khan DA. Assessment of patients who have experienced anaphylaxis: a 3-year survey. Mayo Clin Proc. 1994; 69:16-23. [PubMed: 7903730]

3. May CD. Objective clinical and laboratory studies of immediate hypersensitivity reactions to foods in asthmatic children. J Allergy Clin Immunol. 1976; 58:500-515. [PubMed: 61222]

4. Sampson HA. Food allergy. Part 1: immunopathogenesis and clinical disorders. J Allergy Clin Immunol. 1999; 103:717-728. [PubMed: 10329801]

5. Aalberse RC, Koshte V, Clemens JG. Immunoglobulin E antibodies that crossreact with vegetable foods, pollen, and Hymenoptera venom. J Allergy Clin Immunol. 1981; 68:356-364. [PubMed: 7298999]

6. Fötisch K, Vieths S. N- and O-linked oligosaccharides of allergenic glycoproteins. Glycoconj J. 2001; 18:373-390. [PubMed: 11925505]

7. Prenner C, Mach L, Glössl J, März L. The antigenicity of the carbohydrate moiety of an insect glycoprotein honey-bee (Apis mellifera) venom phospholipase A2. The role of $\alpha 1,3$-fucosylation of the asparagine-bound N-acetylglucosamine. Biochem J. 1992; 284:377-380. [PubMed: 1376112]

8. Kochuyt AM, Van Hoeyveld EM, Stevens EA. Prevalence and clinical relevance of specific immunoglobulin E to pollen caused by sting-induced specific immunoglobulin E to cross-reacting carbohydrate determinants in Hymenoptera venoms. Clin Exp Allergy. 2005; 35:441-447. [PubMed: 15836751]

9. van Ree R, Aalberse RC. Pollen-vegetable food crossreactivity: serological and clinical relevance of crossreactive IgE. J Clin Immunoassay. 1993; 16:124-130.

10. Altmann F. The role of protein glycosylation in allergy. Int Arch Allergy Immunol. 2007; 142:99115. [PubMed: 17033195]

11. Chung CH, Mirakhur B, Chan E, Le QT, Berlin J, Morse M, et al. Cetuximab-induced anaphylaxis and IgE specific for galactose- $\alpha-1,3$-galactose. N Engl J Med. 2008; 358:1109-1117. [PubMed: 18337601]

12. Simon PM, Neethling FA, Taniguchi S, Goode PL, Zopf D, Hancock WW, et al. Intravenous infusion of Gal $\alpha 1-3 \mathrm{Gal}$ oligosaccharides in baboons delays hyperacute rejection of porcine heart xenografts. Transplantation. 1998; 65:346-353. [PubMed: 9484750]

13. Galili U, Rachmilewitz EA, Peleg A, Flechner I. A unique natural human IgG antibody with antialpha-galactosyl specificity. J Exp Med. 1984; 160:1519-1531. [PubMed: 6491603]

14. Qian J, Liu T, Yang L, Daus A, Crowley R, Zhou Q. Structural characterization of N-linked oligosaccharides on monoclonal antibody cetuximab by the combination of orthogonal matrixassisted laser desorption/ionization hybrid quadrupole-quadrupole time-of-flight tandem mass spectrometry and sequential enzymatic digestion. Anal Biochem. 2007; 364:8-18. [PubMed: 17362871]

15. Spiro RG, Bhoyroo VD. Occurrence of $\alpha$-D-galactosyl residues in the thyroglobulins from several species. Localization in the saccharide chains of the complex carbohydrate units. J Biol Chem. 1984; 259:9858-9866. [PubMed: 6086655]

16. Thall A, Galili U. Distribution of Gal $\alpha 1-3 \mathrm{Gal} \beta 1-4 \mathrm{GlcNAc}$ residues on secreted mammalian glycoproteins (thyroglobulin, fibrinogen, and immunoglobulin $\mathrm{G}$ ) as measured by a sensitive solid-phase radioimmunoassay. Biochemistry. 1990; 29:3959-3965. [PubMed: 2354167]

17. Reefer AJ, Satinover SM, Wilson BB, Woodfolk JA. The relevance of microbial allergens to the IgE antibody repertoire in atopic and nonatopic eczema. J Allergy Clin Immunol. 2007; 120:156163. [PubMed: 17507082]

18. Cavalier E, Carlisi A, Chapelle JP. Evaluation of the analytical performance of the ImmunoCAP 250 (Sweden Diagnostics) [in French]. Ann Biol Clin (Paris). 2006; 64:91-94. [PubMed: 16420996]

19. Erwin EA, Custis NJ, Satinover SM, Perzanowski MS, Woodfolk JA, Crane J, et al. Quantitative measurement of $\operatorname{IgE}$ antibodies to purified allergens using streptavidin linked to a high-capacity solid phase. J Allergy Clin Immunol. 2005; 115:1029-1035. [PubMed: 15867862]

20. Chapman MD, Aalberse RC, Brown MJ, Platts-Mills TA. Monoclonal antibodies to the major feline allergen Fel d 1. J Immunol. 1988; 140:812-818. [PubMed: 3276780] 
21. van der Veen MJ, van Ree R, Aalberse RC, Akkerdaas J, Koppelman SJ, Jansen HM, et al. Poor biologic activity of cross-reactive IgE directed to carbohydrate determinants of glycoproteins. J Allergy Clin Immunol. 1997; 100:327-334. [PubMed: 9314344]

22. Macher BA, Galili U. The Gal $\alpha 1,3$ Galb1,4GlcNAc-R ( $\alpha$-Gal) epitope: a carbohydrate of unique evolution and clinical relevance. Biochim Biophys Acta. 2008; 1780:75-88. [PubMed: 18047841]

23. Paschinger K, Fabini G, Schuster D, Rendić D, Wilson IB. Definition of immunogenic carbohydrate epitopes. Acta Biochim Pol. 2005; 52:629-632. [PubMed: 16175237]

24. Fiocchi A, Restani P, Riva E, Restelli AR, Biasucci G, Galli CL, et al. Meat allergy: I- specific IgE to BSA and OSA in atopic, beef sensitive children. J Am Coll Nutr. 1995; 14:239-244. [PubMed: 8586772]

25. Verdaguer J, Corominas M, Bas J, Valls A, Mestre M, Romeu A, et al. IgE antibodies against bovine serum albumin in a case of eosinophilic gastroenteritis. Allergy. 1993; 48:542-546. [PubMed: 8238812]

26. Werfel SJ, Cooke SK, Sampson HA. Clinical reactivity to beef in children allergic to cow's milk. J Allergy Clin Immunol. 1997; 99:293-300. [PubMed: 9058683]

27. Galili $U$. The $\alpha$-gal epitope and the anti-Gal antibody in xenotransplantation and in cancer immunotherapy. Immunol Cell Biol. 2005; 83:674-686. [PubMed: 16266320]

28. Sampson HA, Rosen JP, Selcow JE, Mendelson L, Grodofsky MP, Factor JM, et al. Intradermal skin tests in the diagnostic evaluation of food allergy. J Allergy Clin Immunol. 1996; 98:714-715. [PubMed: 8828554]

29. O’Neil BH, Allen R, Spigel DR, Stinchcombe TE, Moore DT, Berlin JD, et al. High incidence of cetuximab-related infusion reactions in Tennessee and North Carolina and the association with atopic history. J Clin Oncol. 2007; 25:3644-3648. [PubMed: 17704414]

30. Owera R, Gill A, Haddadin S, Khozouz R, Perry MC. High incidence of hypersensitivity reactions to cetuximab infusions in mid-Missouri: association with prior history of atopy. J Clin Oncol. 2008; 26 suppl abstract 20747.

31. van Nunen S, O'Connor K, Fernando S, Clarke L, Boyle RX. The association between Ixodes holocyclus tick bite reactions and red meat allergy [abstract]. Intern Med J. 2007; 37:A132.

32. Adédoyin J, Grönlund H, Oman H, Johansson SG, van Hage M. Cat IgA, representative of new carbohydrate cross-reactive allergens. J Allergy Clin Immunol. 2007; 119:640-645. [PubMed: 17336613]

33. Sabbah A, Rousseau C, Lauret MG, Drouet M. The pork-cat syndrome: RAST inhibition test with Fel d 1 [in French]. Allerg Immunol (Paris). 1994; 26:259-260. [PubMed: 7986339]

34. Mamikoglu B. Beef, pork, and milk allergy (cross-reactivity with each other and pet allergies). Otolaryngol Head Neck Surg. 2005; 133:534-537. [PubMed: 16213925] 

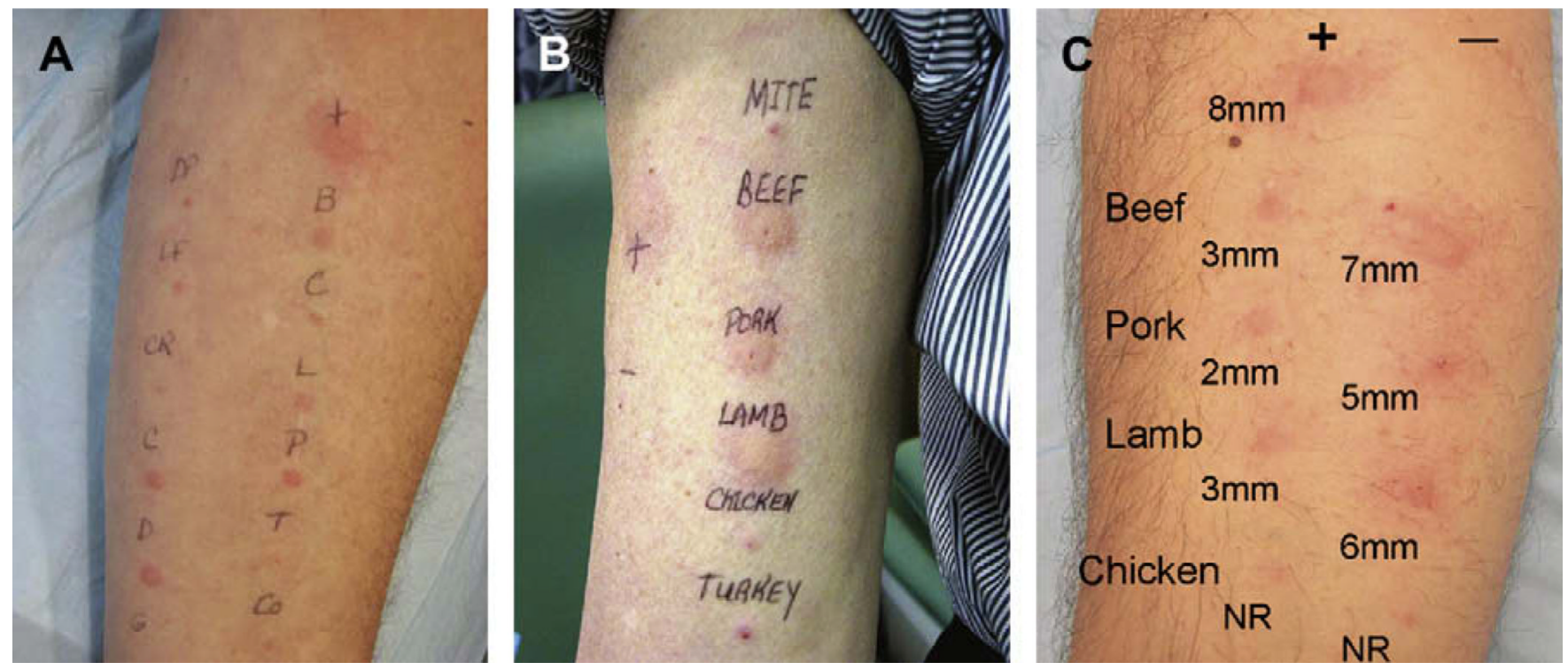

FIG 1.

Representative SPT and intradermal test results in patients with IgE antibodies to $\alpha$-gal. A, SPTs were performed on the volar surface of the arm with commercially available skin testing reagents at 1:20 wt/vol after histamine reactivity (denoted by + ) was verified. Right column of SPTs: $B$, beef; $C$, chicken; $L$, lamb; $P$, pork; $T$, turkey, $C o$, codfish. Left column of SPTs: DP, Dermatophagoides pteronyssinus; DF, Dermatophagoides farinae; $C R$, cockroach; $C$, cat; $D$, dog; $G$, grass. B, Intradermal testing was performed with $0.03 \mathrm{~mL}$ of a 1:100 dilution of commercially available reagents (ie, 1:2000 wt/vol) with a 25-gauge needle. C, SPTs with commercially available reagents (left) and fresh meat extract (right) in which values in millimeters represent the greatest diameter of wheal response. $N R$, Nonreactive. The experiments in Fig 1, $A$ and $B$, were performed on the same patient during a single clinic visit and were measured 15 minutes after placement. Negative controls were $50 \%$ glycerin/saline for SPTs and buffered saline for intradermal tests. 
A
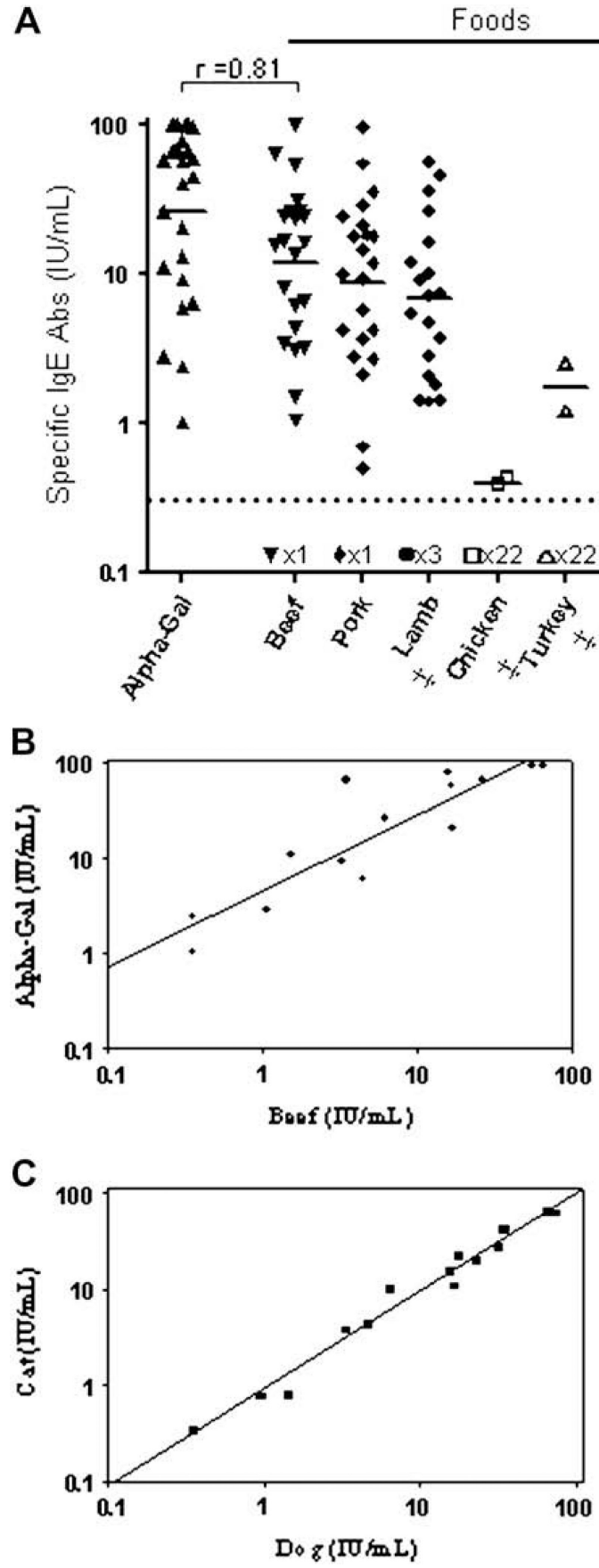

Inhalants

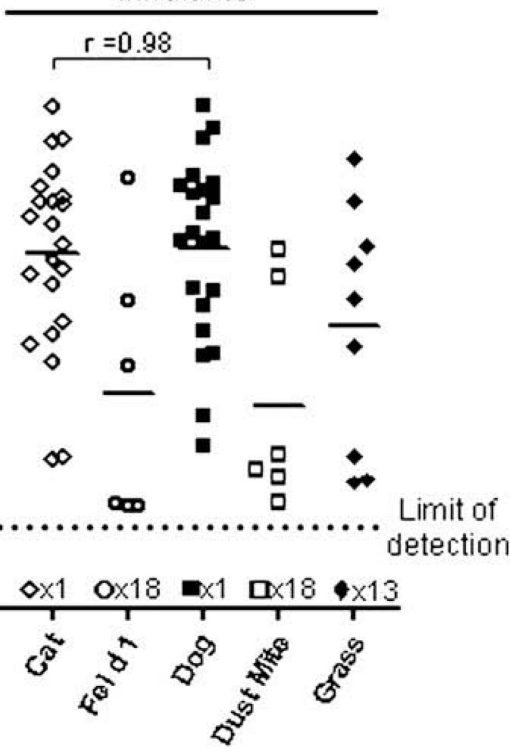

D

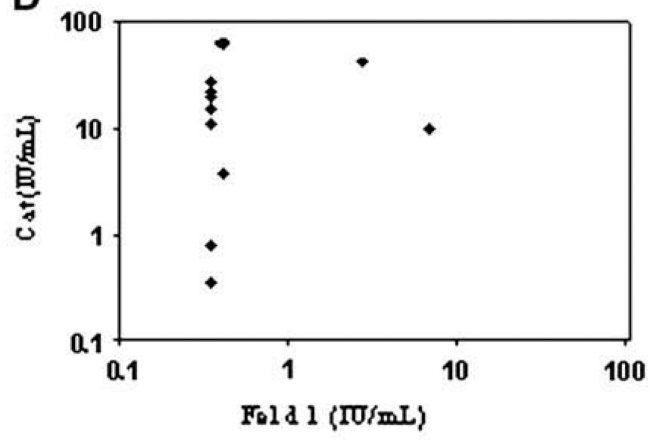

FIG 2.

A, IgE antibody binding to allergens in serum samples from 24 patients with IgE antibodies to $\alpha$-gal. The horizontal lines indicate geometric mean values. Numbers below the limit of detection indicate the number of negative values for each allergen. Four results for $\alpha$-gal were greater than $100 \mathrm{IU} / \mathrm{mL}$ and are listed in Table II. One result each for beef, cat, and dog were greater than $100 \mathrm{IU} / \mathrm{mL}$. $\ddagger$ Chicken, turkey, and fish have a significantly lower prevalence of positive results $(P<.01)$ compared with $\alpha$-gal, beef, pork, and lamb by means of $\chi^{2}$ analysis. Abs, Antibodies. B, Correlation of IgE antibodies to $\alpha$-gal and IgE antibodies to beef in patients with $\operatorname{IgE}$ antibodies to $\alpha$-gal. C, Correlation of IgE antibodies to cat and 
IgE antibodies to dog in patients with IgE antibodies to $\alpha$-gal. D, Correlation of $\operatorname{IgE}$ antibodies to cat and $\operatorname{IgE}$ to Fel $\mathrm{d} 1$ in patients with $\operatorname{IgE}$ antibodies to $\alpha$-gal. 
A Symptomatic subjects

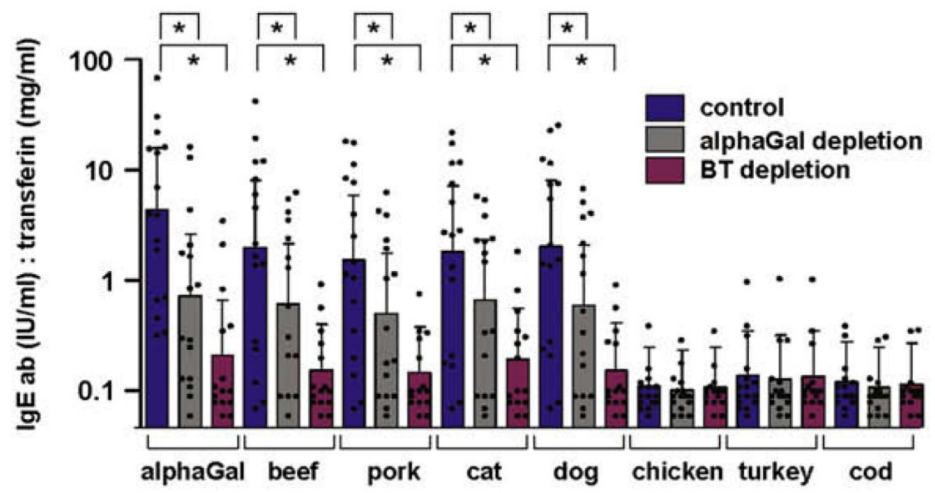

B AD subjects

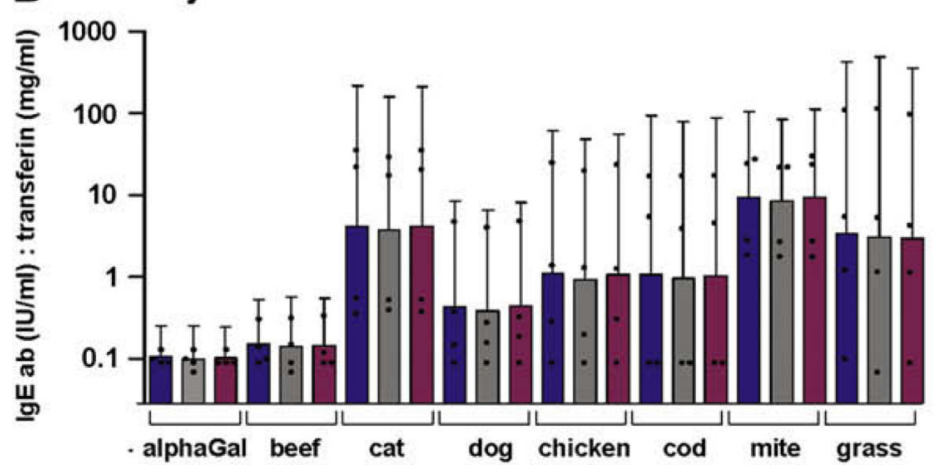

C

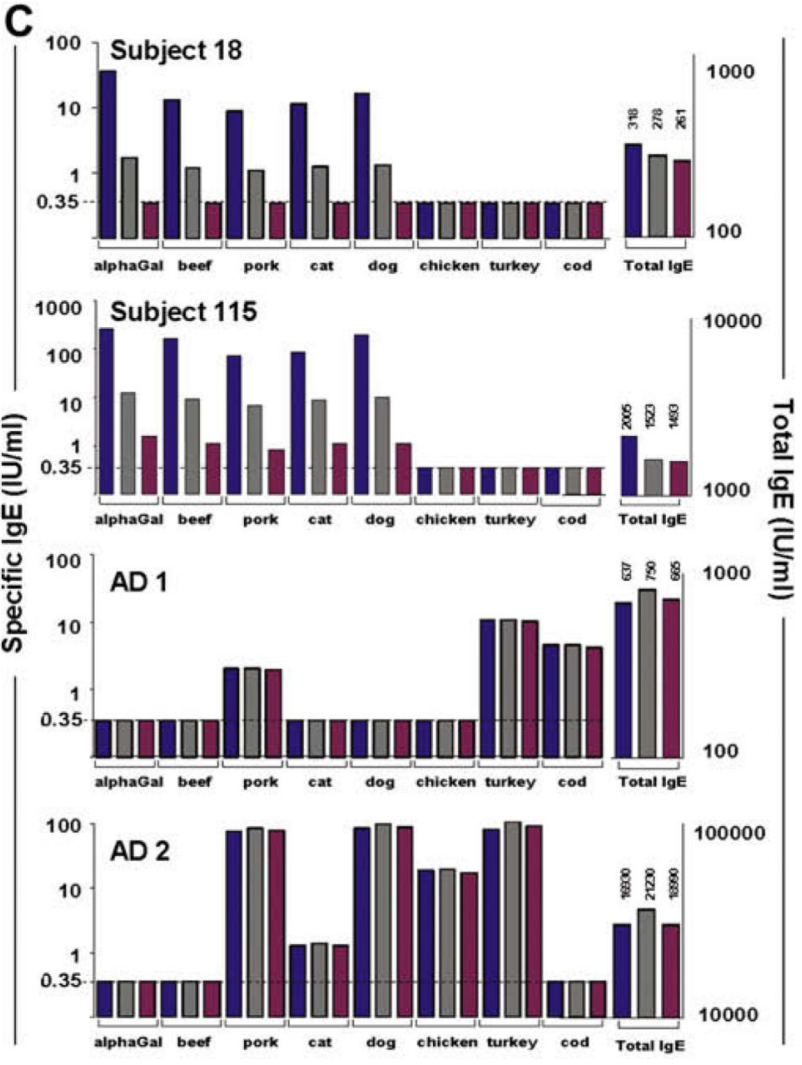

FIG 3.

Absorption of sera with sepharose-bound $\alpha$-gal or sepharose-bound bovine thyroglobulin $(B T)$. A, Sera from patients $(n=8)$ with $\operatorname{IgE}$ antibodies to $\alpha$-gal were incubated overnight with $\alpha$-gal bound to sepharose beads (gray bars), bovine thyroglobulin bound to sepharose beads (red bars), or mock-coupled sepharose beads (blue bars) expressed as specific IgE antibodies and adjusted for transferrin concentration. Error bars indicate $95 \%$ CIs. B, Sera from patients $(\mathrm{n}=4)$ with atopic dermatitis $(A D)$ treated as described for Fig 3, $A$. C, Sera from 2 individual patients with IgE antibodies to $\alpha$-gal (subjects 18 and 115) and 2 patients with atopic dermatitis ( $A D 1$ and $A D 2)$ treated as described for Fig 3, $A$. 


\section{TABLE I}

Overview of patient screening

\begin{tabular}{lrrrr}
\hline $\begin{array}{l}\text { Patients with delayed } \\
\text { histories }\end{array}$ & $\begin{array}{r}\text { No. of } \\
\text { patients }\end{array}$ & $\begin{array}{r}\text { No. of patients with >1.0 IU/ } \\
\mathbf{m L} \\
\text { IgE antibody to } \alpha \text {-gal }\end{array}$ & $\begin{array}{r}\text { No. of patients with <1.0 IU/ } \\
\mathbf{m L} \\
\text { IgE antibody to } \alpha \text {-gal }\end{array}$ & $\begin{array}{r}\text { No. of patients negative for } \\
\text { IgE antibody to } \alpha \text {-gal }\end{array}$ \\
\hline Initial screening & 4 & 4 & 0 & 0 \\
\hline UVa cases & 243 & 15 & 21 & 207 \\
\hline Springfield, MO & 5 & 5 & 0 & 0 \\
\hline
\end{tabular}

$U V a$, University of Virginia Allergy Clinic.

* All enrolled patients $(n=24)$ had IgE antibodies to a-gal of greater than $1.0 \mathrm{IU} / \mathrm{mL}$. 


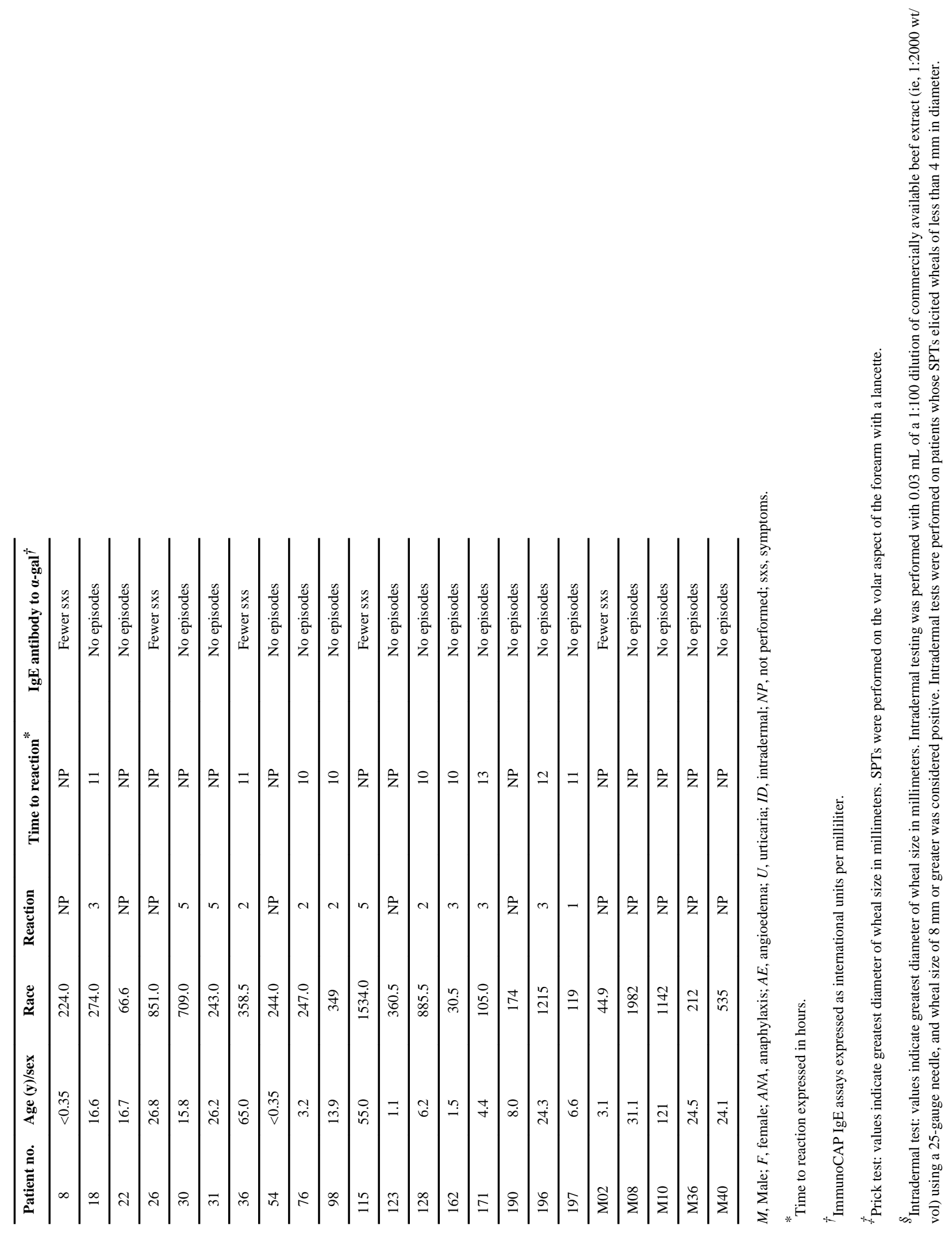


TABLE III

Skin testing in patients with serum IgE antibodies to $\alpha$-gal ${ }^{*}$

\begin{tabular}{lccl}
\hline & \multicolumn{2}{c}{ SPT $^{\dagger}$} & \\
\cline { 2 - 3 } Allergen & Commercial extract $^{\S}$ & Fresh food $^{\prime \prime}$ & Intradermal $^{\dagger}$ \\
\hline Beef & $3 / 10(30)$ & $5 / 5(100)$ & $7 / 7(100)$ \\
\hline Pork & $2 / 9(22)$ & $4 / 5(80)$ & $7 / 7(100)$ \\
\hline Lamb & $4 / 9(44)$ & $5 / 5(100)$ & $5 / 5(100)$ \\
\hline Chicken & $0 / 9(0)$ & $0 / 5(0)$ & $0 / 9(0)$ \\
\hline Turkey & $0 / 8(0)$ & - & $0 / 8(0)$ \\
\hline Fish & $0 / 8(0)$ & - & $0 / 8(0)$ \\
\hline Milk & $2 / 8(25)$ & - & $6 / 6(100)$ \\
\hline Cat & $3 / 10(30)$ & - & $7 / 7(100)$ \\
\hline Dog & $3 / 10(30)$ & - & $7 / 7(100)$ \\
\hline Dust mite & $1 / 10(10)$ & - & $2 / 9(22)$ \\
\hline
\end{tabular}

Results are expressed as number with positive test result/total tested followed by percentage positive in parentheses.

${ }^{\dagger}$ SPTs were performed on the volar aspect of the forearm with a lancette, and a wheal size of $4 \mathrm{~mm}$ or greater in diameter was considered positive.

* Intradermal tests were performed with $0.03 \mathrm{~mL}$ of a 1:100 dilution of commercially available reagents (ie, 1:2000 wt/vol) using a 25 -gauge needle, and a wheal size of $8 \mathrm{~mm}$ or greater was considered positive. Intradermal tests were performed on patients whose SPT results were nonreactive or less than $4 \mathrm{~mm}$ in diameter.

$\S$ Commercially available skin testing reagents used at 1:20 wt/vol were purchased from Greer (Lenoir, NC).

"Fresh beef, pork, lamb, and chicken were procured from a local butcher on each day of testing. The fresh-food extracts were prepared as an approxim ate $10 \% \mathrm{wt} / \mathrm{vol}$ slurry in $50 \%$ glycerin/saline. 